\title{
O Benchmarking Corporativo: O Benchmarking Financeiro e a Gestão Estratégica das Empresas
}

\section{Resumo}

O texto analisa as diferentes formas de benchmarking descrevendo o conjunto de parâmetros financeiros mais freqüentemente utilizados e seu alinhamento com o processo de Administração estratégica nas empresas. Benchmarking é o processo usado em Administração e, particularmente, em Administração Estratégica, no qual as empresas usam as empresas líderes, tanto do seu setor como fora dele, como modelos para desenvolver e aperfeiçoar suas práticas gerenciais. Além das estratégias em si, o processo de planejamento estratégico está freqüentemente sujeito à atividade de referência (benchmarking). As limitações da análise financeira tradicional por meio de índices têm incentivado a aplicação da análise por meio de múltiplos, com o uso do EVA (Economic Value Added) e do MVA (Market Value Added). O texto conclui indicando que o uso do EVA e do MVA pode se constituir no ponto de convergência do benchmarking financeiro e da Administração Estratégica, articulando os objetivos empresariais com as medidas de desempenho e incentivos financeiros que orientam as decisões gerenciais de modo a garantir a criação de valor para os acionistas e proporcionar às empresas um crescimento sustentável.

\section{Abstract \\ The paper seeks to analyze the different benchmarking approaches describing the most used set of financial parameters and their relationship with the Strategic management process. Benchmarking}

is the approach used in Management practice and especially in Strategic Management by which firms use leading companies - both in and outside their business - as models to develop and improve their managerial practices. Beyond the strategies themselves, the strategic planning process is frequently related to reference practices (benchmarking). The limitations of the traditional financial analysis using indexes have encouraged the use of financial multiples specially the use of EVA (Economic Value Added) and of MVA (Market Value Added). The text indicates that the use of both EVA and MVA can be the convergence point of financial benchmarking with Strategic Management unifying the company's goals with performance and financial incentives measures that guide managerial decisions in order to insure value creation to shareholders and the company's sustainable growth.

Palavras-chave: benchmarking, benchmarking financeiro, múltiplos financeiros, EVA, MVA, administração estratégica.

Key words: benchmarking, financial benchmarking, financial multiples, EVA, MVA, strategic management.

\section{1- Introdução}

O texto que se segue procura analisar as diferentes formas de benchmarking, descrevendo o conjunto de parâmetros financeiros mais freqüentemente utilizados e seu alinhamento com o processo de Administração estratégica nas empresas.

\footnotetext{
${ }^{1}$ Graduado em Engenharia de Produção pela Escola Politécnica (EPUSP-1970), Mestrado em Administração de Empresas pela FGV - SP (EAESP/FGV-1979) e Doutorado no Programa Interunidades em Economia da Energia (EP/FEA/IEE/IF da USP - 2006). Possui curso de extensão em Economia Internacional pela Harvard Business School, Harvard University, Mass., EUA (1968). Consultor da FIPE/FEA/USP. Professor do curso de Administração das Faculdades Integradas "Campos Salles". e-mail: stozzini@terra.com.br
} 


\section{1- Benchmarking e benchmarks}

Em 1989, Richard Lester e pesquisadores do Centro de Desempenho Industrial do MIT (MIT Industrial Performance Center) identificaram as 7 "melhores práticas" e concluíram que as empresas deveriam sair do processo de produção em massa de produtos padronizados. As sete áreas de melhores práticas eram: (LESTER, 1989)

1. melhoria contínua e simultânea em custos, qualidade, serviços e inovação do produto;

2. quebra de barreiras organizacionais entre departamentos;

3. eliminação de níveis gerenciais criando hierarquias organizacionais horizontais ("achatadas");

4. relações mais próximas entre clientes e fornecedores;

5. uso inteligente de novas tecnologias;

6. foco na globalização;

7. melhoria nas habilidades dos recursos humanos.

A busca de "melhores práticas" foi também denominada de "benchmarking" (CAMP, 1989). Um "benchmark" é um ponto de referência para uma medida ${ }^{2}$. Pode-se entender um "benchmark" como uma referência confiável e precisa.

\section{2- Benchmarking e Administração Estratégica}

Benchmarking é um processo usado em Administração e, particularmente, em Administração estratégica, no qual as empresas usam empresas líderes, tanto do seu setor como fora dele, como modelos para desenvolver e aperfeiçoar suas práticas empresariais. O benchmarking estuda de maneira sistemática as melhores empresas e usa suas melhores práticas como padrão de comparação, padrão a ser alcançado ou mesmo superado.

$\mathrm{O}$ benchmarking reconhece que nenhuma empresa é excepcional em tudo o que faz. Daí ser um processo contínuo envolvendo empresas de qualquer setor e qualquer país. O raciocínio é o de que a busca contínua das melhores práticas nas melhores empresas ao redor do mundo, fará com que sua empresa se transforme em uma empresa excepcional.

É importante salientar-se o uso da prática de referência (benchmarking) na definição de resultados finais que caracterizam o sucesso de uma organização - medidas de desempenho - e na identificação das estratégias funcionais utilizadas por aquelas empresas que possuem vantagens competitivas (aperfeiçoamento). Spendolini (1993:33) conclui que:

\begin{abstract}
Além das estratégias em si, o processo de planejamento estratégico está freqüentemente sujeito à atividade de referência (benchmarking). Esse assunto [tema] não apenas envolve o processo de estabelecimento de um plano básico, como também considera o modo como as organizações reagem estrategicamente às mudanças como a introdução de novas tecnologias, ações competitivas e oportunidades de mercado.
\end{abstract}

As considerações acima podem ser ilustradas pela Figura 1 que segue:

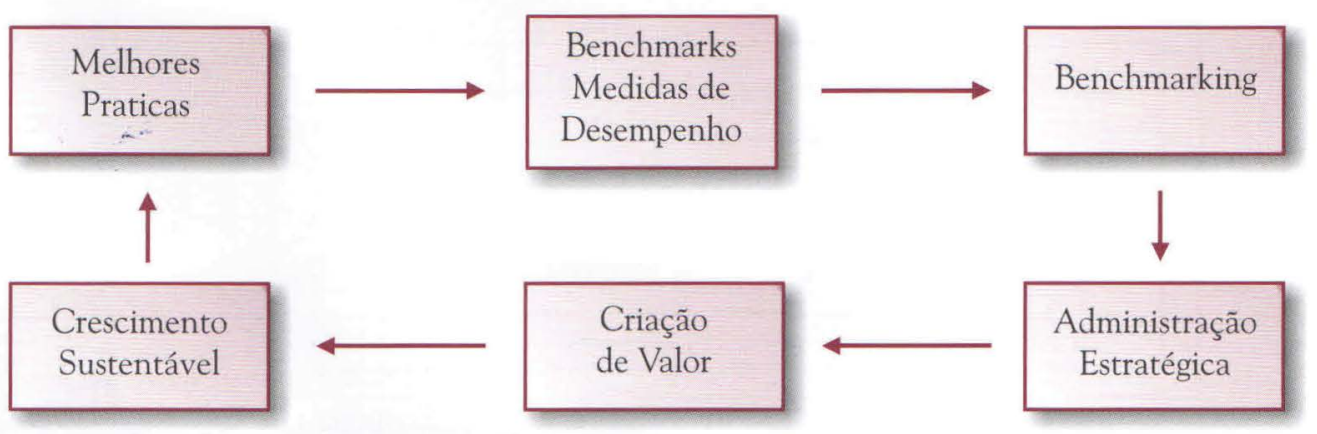

Figura 1- Benchmarking e Administração Estratégica

${ }^{2}$ A expressão provavelmente se origina da prática de realizar medidas da dimensão de um objeto sobre uma bancada ( workbench em inglês) com uma escala graduada ou instrumento semelhante e usando a superfície da bancada como a origem para essas medidas (em http://www.bambooweb.com/articles/b/e/Benchmark.html). 


\section{3- Tipos de benchmarking}

Toda função ou tarefa de uma empresa pode ser objeto de benchmarking, da produção ao marketing, às compras, à administração da tecnologia da informação, aos serviços aos consumidores, entre outras.

Há vários tipos de benchmarking, cada um deles caracterizado por seu objetivo. (LACOMBE; HEILBORN, 2003:471). Os principais tipos de benchmarking são: o interno, o externo e o benchmarking genérico.

Benchmarking interno é a comparação de operações semelhantes dentro de sua própria organização. Ocorre quando uma organização grande e diversificada (departamentalizada ou multidivisional) busca identificar as melhores práticas internas dentro da própria organização. $\mathrm{O}$ conhecimento interno das melhores práticas passa a ser a linha mestra de todas as medições.

O benchmarking externo, por sua vez, pode incluir o benchmarking competitivo - uma comparação com seus próprios concorrentes - e o benchmarking funcional - uma comparação de métodos com organizações que têm processos similares em setores diferentes de atuação.

$\mathrm{O}$ benchmarking competitivo tem como objetivo identificar informações específicas sobre os concorrentes diretos da organização, seus produtos, processos e resultados, comparando-os com aqueles da própria organização. Trata-se de uma atividade sensível, na medida em que o conceito de benchmarking competitivo é diferente da análise competitiva tradicional que, em geral, é conduzida "intramuros".

Já o benchmarking funcional envolve um universo mais amplo pela identificação das melhores práticas em qualquer tipo de organização - não necessariamente concorrente - conhecida pela reputação de excelência em uma atividade específica, objeto do processo de referência (benchmarking).

O benchmarking genérico busca comparar métodos e processos de trabalho com aqueles de empresas consideradas inovadoras, objetivando identificar as melhores práticas.

Alguns autores denominam o benchmarking de "benchmarking das melhores práticas" ou benchmarking de processo para distingui-lo daquilo que foi denominado de "benchmarking competitivo". O benchmarking competitivo é usado na análise da concorrência. Ao pesquisar seus concorrentes diretos, também se pesquisa a melhor empresa no setor. Esta empresa - referência (benchmark) - é então usada como um padrão de comparação quando se avalia a empresa e seus concorrentes diretos. (Benchmarking, 2005)

Os diferentes tipos de benchmarking podem ser visualizados na Figura 2 que segue:

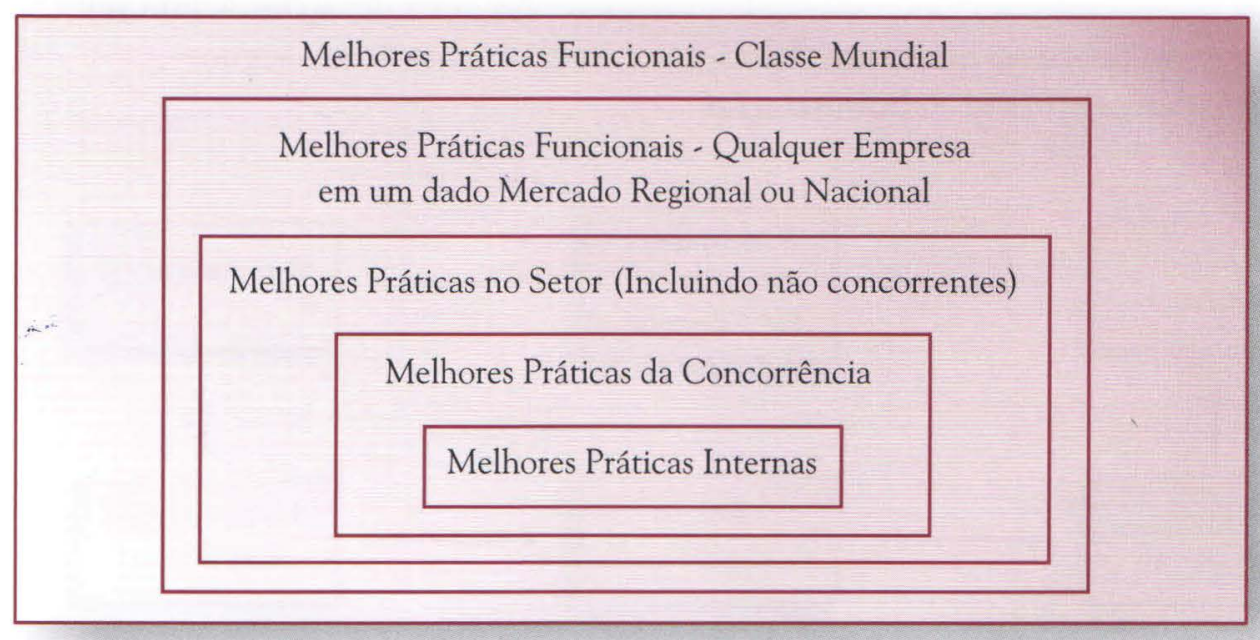

Figura 2- Tipos de benchmarking - de dentro para fora da organização. Adaptado de SPENDOLINI (1993:24) 
De acordo com Spendolini (1993:26-33), da visão dos diferentes tipos de benchmarking conclui-se que as vantagens de sua aplicação podem ser descritas no âmbito das mudanças dos padrões organizacionais, abrangendo as seguintes atividades: (i) planejamento estratégico; (ii) previsão; (iii) novas idéias; (iv) comparações entre produtos/processos e (v) o estabelecimento de objetivos.

Em termos práticos, segundo Sisson; Arrowsmith; Marginson (2003:15), o benchmarking pode se apresentar sob três formas de complexidades variadas. A primeira delas é o "benchmarking de desempenho", que envolve comparações quantitativas de medidas de entrada e/ou saída. A segunda é o "benchmarking de processo", que engloba um escrutínio detalhado da eficiência de processos e atividades de um negócio em particular, fazendo uso de grupos específicos de pesquisas, juntamente com arranjos tais como o credenciamento de padrões de qualidade. A terceira forma é o "benchmarking estratégico", estreitamente relacionado com os conceitos de aprendizagem organizacional e "da organização que aprende" (learning organization). Essencialmente significa comparar as forças impulsionadoras das organizações de sucesso, incluindo liderança e a administração da mudança, a fim de identificar possíveis estratégias alternativas e maneiras de melhorar o desempenho.

\section{4- O processo de benchmarking}

O processo de benchmarking, em geral, é constituído das seguintes etapas:

1- Identificação das áreas problemáticas - dado que o benchmarking pode ser aplicado a qualquer processo ou função empresarial, uma gama de técnicas de pesquisa pode ser necessária. Essas técnicas podem incluir conversas informais com clientes, empregados ou fornecedores; técnicas de pesquisa exploratória como pesquisa qualitativa; ou pesquisas mais detalhadas como pesquisa de mercado, pesquisa quantitativa, entrevistas, questionários, análise de reengenharia, mapeamento de processos, relatórios de variações no controle de qualidade ou análise de índices financeiros.
2- Identificação das organizações que são líderes nessas áreas. Busca-se identificar a melhor em qualquer setor ou indústria e em qualquer país.

3- Estudo e análise de suas melhores práticas. que pode implicar na necessidade de visitas às organizações selecionadas.

4- Implementação das melhores práticas. Delegação da responsabilidade para a ação individual ou forças-tarefa. Estabelecimento de objetivos mensuráveis que devem ser alcançados dentro de um período de tempo especificado.

5- Repetição. O processo de benchmarking é contínuo. As melhores práticas podem sempre ser aperfeiçoadas.

\section{5- Benchmarking financeiro}

Podem-se identificar três abordagens principais para o benchmarking financeiro:

-a análise tradicional por meio de índices financeiros extraídos das demonstrações financeiras mais comuns;

-a análise por meio de múltiplos e

- a análise utilizando os indicadores de "lucro econômico" (EVA/MVA).

1.5.1- Análise tradicional por meio de índices financeiros. A clássica análise dos demonstrativos financeiros

A tradicional análise financeira tem sido conduzida por meio do cálculo de índices baseados nas demonstrações financeiras mais comuns: Demonstrativo de Resultado do Exercício (DRE), Balanço Patrimonial (BP) e o Demonstrativo de Origem e Aplicação de Recursos (DOAR). Este tipo de análise busca interpretar os índices financeiros para avaliar o desempenho e a situação da empresa.

A análise por meio de índices pode envolver duas dimensões: a comparação da empresa com ela mesma ao longo do tempo (análise de série temporal) e a comparação dos índices financeiros entre diferentes empresas em um dado instante (análise cross-seccional). 
Neste ultimo caso, o desempenho da empresa pode ser comparado com a empresa líder do setor, com o objetivo de identificar as principais diferenças operacionais, as quais, se modificadas, poderão aumentar sua eficiência. Ou então se pode comparar o desempenho da empresa sob análise com os denominados índices médios do setor (indústria). (GITMAN, 2002:103).

Segundo Gitman (2002:105), a abordagem mais informativa da análise realizada por meio de índices é aquela que combina a análise temporal com a evolução da indústria, ou seja, compara a evolução de índices da empresa com a evolução dos índices do setor.

Diversos índices podem ser desenvolvidos, a fim de atender a diferentes objetivos e a diferentes grupos de partes interessadas no desempenho da empresa. Em geral, costuma-se subdividir os índices financeiros em quatro grupos ou categorias básicas: índices de liquidez, de atividade, de endividamento e de lucratividade.

Os índices de liquidez medem a capacidade que a empresa tem de cumprir suas obrigações de curto prazo no vencimento. Os índices, ou indicadores de atividade, buscam demonstrar a rapidez com que a empresa é capaz de transformar seus ativos em receitas de venda ou caixa. Os índices de endividamento indicam o montante de recursos de terceiros utilizados. Buscam demonstrar não apenas o tamanho relativo da dívida dentro da sua estrutura de capital, como também seu perfil (prazos). Os índices de lucratividade buscam relacionar as diversas formas de medição do lucro com suas vendas, seus ativos, seu patrimônio líquido ou ao valor de sua ação.

Os índices de liquidez, atividade e de endividamento, buscam medir, fundamentalmente, risco. Os índices de lucratividade, o retorno.

Sabe-se que nenhum índice isoladamente é adequado para avaliar os mais diversos aspectos relacionados à situação financeira da empresa. Embora Gitman (2002:125) sugira duas abordagens para uma análise "completa" de índices - o sistema DUPONT e a análise geral de índices ${ }^{3}$ - uma das críticas mais importantes à abordagem da análise por meio de índices é a de que apresenta uma visão estática da empresa, quando o que se busca é uma visão dinâmica de seu desempenho futuro.

Em outras palavras: não existe muito valor na utilização destes (índices) como fotografias da empresa. Eles devem ser observados como um filme, no qual todos os capítulos, período a período, formam o conjunto da obra. Só assim uma avaliação mais completa pode ser realizada, sobretudo em termos prospectivos. PÓVOA (2004:61).

\subsection{2- Análise por meio de múltiplos.} A avaliação relativa

As limitações identificadas na análise tradicional por meio de índices, indicaram a direção de uma abordagem alternativa que incorporasse a dinâmica do ambiente onde as empresas operam.

A abordagem por múltiplos baseia-se no conceito de que ativos semelhantes devem ter preços semelhantes. A avaliação relativa busca analisar uma empresa usando comparações padronizadas de mercado. Neste contexto, os valores dos múltiplos de comparação incorporam dois aspectos fundamentais: o risco total da empresa e o potencial de crescimento de lucros.

Portanto, de forma geral, os múltiplos apresentam relação inversa com o risco total da empresa quanto menor o risco percebido, maior tende a ser o múltiplo - e relação direta com o crescimento futuro de lucros - quanto maior a expectativa de crescimento, maioromúltiplo. (PÓVOA,2004:288).

\subsubsection{1- Tipos de múltiplos}

Os múltiplos podem ser agrupados nas seguintes categorias:

\footnotetext{
${ }^{3}$ Segundo o autor, cada uma dessas abordagens tem seu mérito. "O sistema DuPont funciona como uma técnica de busca que ajuda a localizar as áreas-chaves responsáveis pelo desempenho financeiro da empresa. A abordagem da análise geral tende a focalizar todos os aspectos das atividades financeiras da empresa, a fim de identificar as áreas-chaves de responsabilidade." (GITMAN, 2002:125)
} 
i. múltiplos de valor empresarial também denominados múltiplos da firma;

ii. múltiplos de valor de mercado também denominados múltiplos do acionista;

iii. múltiplos híbridos;

iv. múltiplos técnicos ou múltiplos reais que incorporam relações específicas de um setor empresarial.

v. Os principais múltiplos de valor empresarial são:

$\mathrm{VE}^{4} /$ Ativo total

VE/Valor patrimonial dos ativos

$\mathrm{VE} /$ receita

$\mathrm{VE} / \mathrm{EBITDA}^{5}$

$\mathrm{VE} / \mathrm{EBIT}^{6}$

VE/NOPAT ${ }^{7}$

VE/Fluxo de caixa para a empresa

Exemplos dos principais múltiplos de valor de mercado:

- preço da ação/ valor patrimonial da ação (VPA) ou Valor de mercado/Patrimônio Líquido;

- preço da ação/ lucro líquido por ação (índice preço/lucro $=\mathrm{P} / \mathrm{L}$ );

- preço da ação/ fluxo de caixa para o acionista.

Estão entre os múltiplos híbridos:

- valor de Mercado/Receita líquida da

empresa;

- valor da firma/Receita.

São exemplos de múltiplos técnicos:

- EV/MWh (setor elétrico);

- receita líquida de Vendas/Número de

funcionários (vários setores);

- vendas/m2 (setor de comércio varejista).
1.5.2.2- Vantagens e desvantagens da avaliação por múltiplos

As principais vantagens do uso de múltiplos, de acordo com Martelanc, Pasin, Cavalcante (2005:197) são:

i. simplicidade: são necessários apenas dois valores para a avaliação de uma empresa. Bastam dois valores para determinar-se o valor do múltiplo;

ii. rápida incorporação de novas informações: os denominados múltiplos de mercado incorporam todos os dias os impactos de novas informações no valor das empresas abertas;

iii. necessidade de poucas informações na medida em que trabalham com informações básicas sobre a empresa analisada, informações em geral acessíveis e de fácil obtenção, como lucro, EBITDA ou receita de vendas.

Já as principais limitações identificadas no uso de múltiplos - ainda de acordo com aqueles autores - estariam relacionadas com as suas dimensões de precisão e consistência. Os múltiplos podem se mostrar imprecisos na avaliação de empresas com características não comparáveis, ou seja, nem sempre a empresa analisada possui as mesmas características das empresas utilizadas como referência.

Por outro lado, o uso indiscriminado de múltiplos pode levar a um comportamento grupal conhecido como "efeito manada" - que conduziria à determinação de valores distantes do valor efetivo da empresa.

\subsubsection{3-Quais os múltiplos mais} utilizados?

Pesquisa da APIMEC $^{8}$ revela que os avaliadores do mercado utilizam os seguintes múltiplos em ordem de freqüência:

\footnotetext{
${ }^{4} \mathrm{VE}($ valor empresarial $)$ = valor total da empresa = valor de mercado + valor das dívidas financeiras - valor do disponível Também grafado como EV da expressão inglesa "Enterprise Value".

${ }^{5}$ EBITDA $=$ LAJIDA = lucro antes dos juros, imposto de renda, depreciação e amortizações; conceito utilizado como "proxy" da capacidade de geração de caixa operacional pela empresa.

${ }_{7}^{6} \mathrm{EBIT}=\mathrm{LAJIR}=$ lucro antes de juros e impostos.

${ }^{7}$ NOPAT ou NOPLAT $=$ lucro operacional líquido após impostos.

${ }^{8}$ Associação dos Analistas e Profissionais de Investimento do Mercado de Capitais, citada em MARTELANC, PASIN, CAVALCANTE (2005:217).
} 


\begin{tabular}{|c|c|}
\hline $\begin{array}{c}\text { Múltiplos } \\
\text { de }\end{array}$ & $\begin{array}{c}\text { Frequência } \\
\text { de uso (\%) }\end{array}$ \\
\hline EBITDA & 91,8 \\
\hline P/L & 79,6 \\
\hline Preço/VPA & 38,8 \\
\hline
\end{tabular}

Sendo que $42,9 \%$ dos avaliadores utilizam três múltiplos, 26,5\% utilizam dois indicadores e $18,4 \%$ apenas um. A pesquisa não deixa claro se o múltiplo de uma única empresa de referência é preferível ao uso de múltiplos médios, ou medianos de diversas empresas.

Embora a pesquisa revele o prestígio adquirido pelos múltiplos de EBITDA como, por exemplo, VE/EBITDA perante os analistas em todo o mundo, dada a facilidade com que pode ser calculado, Póvoa (2004:314) adverte que

a idéia de facilidade e simplicidade não pode ser confundida com análise rasa e simplória. Por mais que $\mathrm{o}$ analista deseje, em um múltiplo de firma não é possível fugir de aspectos presentes em qualquer processo de 'valuation', como o crescimento do lucro operacional depois dos impostos e o custo médio ponderado de capital.

\subsection{3- EVA/MVA - Os indicadores de "lucro econômico"}

1.5.3.1 - EVA. Conceito. Metodologia de cálculo

A questão, portanto, que se coloca, é da possibilidade de aliar-se a facilidade do cálculo de múltiplos com as dimensões de crescimento do lucro operacional e o custo médio ponderado de capital.

Uma possível resposta à questão seria o uso do denominado valor econômico agregado ou Economic Value Added (EVA). Na área de finanças, o EVA é um método para determinar o valor criado para os acionistas de uma empresa.
Como nos informa Martins (2001:244) "podemos compreender o EVA como uma resposta à necessidade de medidas de desempenho que expressem a adequada criação de riqueza por um empreendimento. Esse conceito foi desenvolvido durante a década de 80 e amplamente divulgado pela obra de Stewart (1991)".

A utilização do conceito de valor econômico agregado (EVA) está associado ao conceito tradicional de "lucro econômico" (economic profit) da teoria econômica, ou seja, é o lucro da empresa após o pagamento dos custos, das despesas e dos tributos necessários à sua operação, deduzidos também o custo do capital utilizado (MARTELANC, PASIN, CAVALCANTE, 2005:237) Ehrbar (1999:2) informa que

$$
\begin{aligned}
& \text { aritmeticamente, é o lucro operacional após } \\
& \text { pagamento de impostos menos os encargos sobre } \\
& \text { o capital, apropriado tanto para endividamento } \\
& \text { quanto para o capital acionário. O que resta é o } \\
& \text { valor em dólares pelo qual o lucro excede ou deixa } \\
& \text { de alcançar o custo do capital utilizado para realizar } \\
& \text { aquele lucro. Este número é o que os economistas } \\
& \text { denominam de lucro residual, o que significa } \\
& \text { exatamente aquilo que implica: é o resíduo que } \\
& \text { sobra depois de todos os custos terem sido cobertos. } \\
& \text { Economistas também se referem a isto como lucro } \\
& \text { econômico ou aluguel econômico. Nós o chamamos } \\
& \text { de EVA, valor econômico adicionado. }
\end{aligned}
$$

Portanto, a metodologia do EVA procura incorporar na apuração do lucro contábil, o conceito de custo de oportunidade e desse modo determinar o lucro econômico.

Pode-se apresentar o EVA de acordo com a seguinte expressão: 
Lucro econômico $=$ EVA $=$ Lucro operacional líquido após os impostos (NOPLAT) - (NOA * WACC)

Onde:

$\mathrm{NOA}=$ Net operating assets $=$ Ativos operacionais líquidos

WACC $=$ custo médio ponderado de capital $=$ Weighted Average Cost of Capital

Ou ainda, os acionistas (quotistas) de uma empresa receberão um valor agregado positivo quando o retorno do capital de suas ações (quotas), empregado nas operações da empresa, é maior do que o custo daquele capital (Economic Value Added, 2005).

Lucro econômico $=$ EVA $=$ Ativos Operacionais Líquidos (NOA) x ((ROIC (\%) - WACC (\%)

$(2)^{9}$

Onde:

$\mathrm{ROIC}=$ retorno sobre o capital investido $=$ Return On Invested Capital

WACC $=$ custo médio ponderado de capital $=$ Weighted Average Cost of Capital

Podem-se representar as considerações acima com a Figura 3 que se segue:

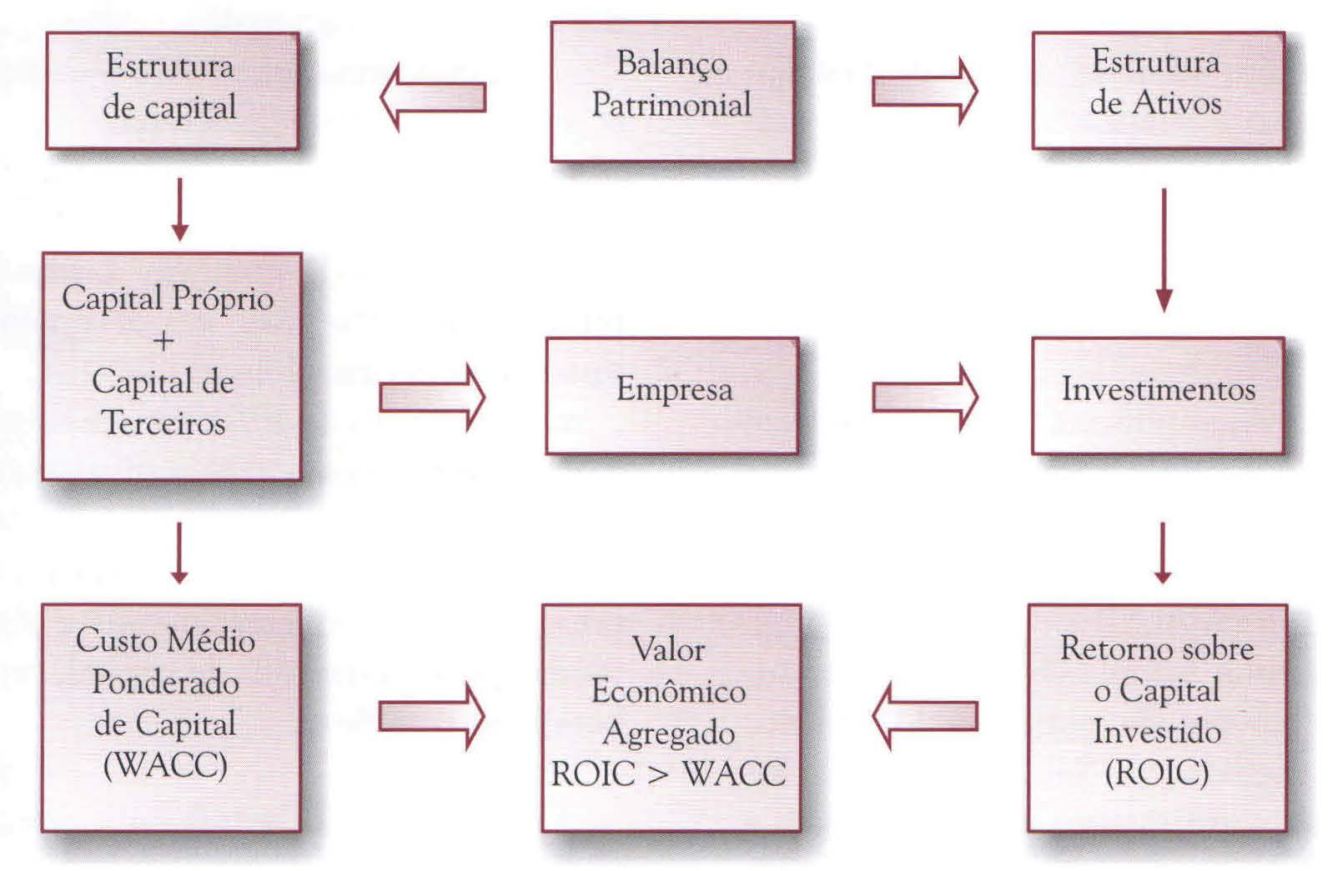

Figura 3- EVA - Valor Econômico Agregado. Adaptado de MARTINS (2001:207)

1.5.3.2- Vantagens e desvantagens do uso do EVA

De acordo com Stewart (1991), as principais vantagens do uso do EVA seriam:

- EVA está intrinsecamente ligado ao valor de mercado;
- EVA fornece medidas significativas para se progredir na criação de valor e servir como benchmark na mensuração do desempenho de toda e qualquer empresa.

Martelanc, Pasin, Cavalcante (2005:240) apresentam - entre outras - as seguintes vantagens na utilização do EVA:

\footnotetext{
${ }^{9}$ As expressões (2) e (1) são equivalentes. De fato, de (2) temos EVA $=$ NOA x $($ ROIC - WACC) $=$ $=$ NOA $\times$ ROIC - NOA $\times$ WACC $=$

$=$ NOA $\times($ NOPLAT/NOA $)-$ NOA $\times$ WACC $=$

$=$ NOPLAT $-($ NOA $x$ WACC) $(1)$
} 
i. explicita o custo de capital empregado nas análises de investimento e desempenho;

ii. define melhor os objetivos da empresa;

iii. permite a integração entre o planejamento estratégico e finanças;

iv. define uma taxa de retorno mínima a ser exigida nos projetos atuais e futuros;

v. divulga e evidencia conceitos como estrutura de capital, custo de capital de terceiros, custo de capital próprio, política de dividendos e custo de manutenção de ativos não operacionais;

vi. estabelece critérios justos para a negociação da remuneração variável dos administradores;

vii. estimula o envolvimento dos administradores na gestão dos negócios e

viii. permite aos administradores de planejamento estratégico a otimização do uso de recursos.

Póvoa (2004: 350) apresenta as seguintes vantagens no uso do EVA:

i. o uso do EVA simplifica a comunicação com funcionários sem formação em Finanças, dá idéia de que a empresa ou um departamento específico deve apresentar um retorno (ROIC) superior ao custo da firma (WACC);

ii. o EVA é uma medida de desempenho superior quando comparada, por exemplo, ao lucro por ação, na medida em que disponibiliza aos administradores instrumentos mais claros para a avaliação: o ROIC para as políticas de investimento e reinvestimento e o WACC para as políticas de financiamento;

iii. possibilidade de aplicação do EVA em unidades operacionais da empresa (divisões, departamentos...) que permite a delegação da responsabilidade direta pela agregação de valor a gerentes e supervisores.

Póvoa (2004:344) identifica algumas limitações no uso do EVA:

i. discrepância entre critérios de cálculo do retorno e custo de capital. O retorno sobre o capital investido é calculado usando-se valores contábeis, enquanto que os custos de capital cor- respondem a média ponderada do custo atual da dívida e dos recursos próprios;

ii. a idade das empresas. Quanto mais antiga for a empresa, maior a possibilidade de distorção do valor do patrimônio líquido, dadas as mudanças nas regras de contabilização nos anos passados em face das altas taxas de inflação no Brasil;

iii. várias adaptações e ajustes devem ser realizadas no valor do lucro operacional após impostos para seu uso no cálculo do retorno sobre investimento tais como:

- itens reconhecidos como despesas nas demonstrações financeiras que devem ser considerados como investimentos;

- despesas não-recorrentes devem ser acrescidas ao lucro operacional;

- despesas sem efeito sobre o caixa devem ser acrescidas ao lucro operacional;

- consolidação de um número de tributos sobre o faturamento e lucro.

iv. o EVA pode conduzir a uma ênfase em retornos de curto prazo em detrimento de uma visão de prazo mais longo;

v. a aplicação do EVA parece se adaptar melhor a empresas com expectativa de crescimento moderado e com estruturas de capital relativamente estáveis. A aplicação do EVA em empresas de elevado crescimento e significativas mudanças na estrutura de capital, apresenta-se bem mais complexa.

\subsubsection{3 - EVA - De volta aos conceitos} básicos

Apesar das evidências favoráveis identificadas pela bibliografia e pela prática ao longo dos anos, a utilização da metodologia do EVA ainda não parece ser uma unanimidade.

Nas palavras do vice-presidente de Finanças do Citigroup, Todd S. Thomson

para manter a atenção voltada ao valor para o acionista, o capital econômico deveria impulsionar as decisões. Há boas justificativas a favor do EVA, mas quanto mais complicamos as ferramentas, mais difícil sua compreensão pelos gerentes e mais difícil para que eles realizem as coisas certas, e mais difícil ainda, avaliar se eles estão realizando as coisas certas. A habilidade de simplificar é importante. 
Sandy Weil, Presidente do Conselho de Administração do Citigroup, vai mais longe, entendendo que as empresas têm usado o EVA de modo muito prescritivo, o que inibe a capacidade de julgamento dos administradores. ${ }^{10}$

Martelanc, Pasin, Cavalcante (2005:239) concluem que:

embora o EVA seja considerado a "melhor" metodologia de avaliação do desempenho, ele não deve ser utilizado com uma métrica isolada. Ao contrário, pode e deve ser calculado em paralelo com outras medidas de rentabilidade, custo, desempenho ealavancagem, já que pode ser explicado e entendido em detalhes por meio desses outros indicadores.

Como nos informa Martins (2001:246)

o EVA, portanto, não se constitui numa novidade propriamente dita, mas parece estar recuperando conceitos elementares, intuitivos e fundamentais, que talvez tenham caído no esquecimento da prática gerencial coletiva. $O$ resgate da essência, da base, do sentido, geralmente produz uma forte atração, especialmente em um período em que a virtualidade possui uma presença significativa no cotidiano social. Essa indicação talvez se aproxime da justificativa para grande penetração no mercado que o EVA tem alcançado.

\subsubsection{4- MVA. Conceito. Metodologia de} cálculo

O MVA (Market Value Added) - valor de mercado adicionado ou agregado - representa a diferença entre o valor de mercado das ações da empresa adicionado ao valor de mercado da sua dívida em um dado instante subtraído do capital total investido. (PÓVOA, 2004:353).

Dado que - no caso brasileiro - o autor considera o valor de mercado da dívida como o seu valor contábil, o MVA reduz-se à diferença entre o valor de mercado das ações e o capital próprio empregado.
Já Martelanc, Pasin, Cavalcante (2005:261) entendem o MVA como o resultado da diferença entre o valor de mercado do capital do acionista, em uma determinada data, subtraído do capital investido pelo acionista na mesma data, que pode ser representado pelo patrimônio líquido contábil.

Chega-se, então, ao conceito de MVA, cuja proposta se consubstancia na mensuração da riqueza gerada por um empreendimento, em termos de percepção do mercado relativa ao valor de seus títulos mobiliários.(MARTINS, 2001:248). Consequentemente, sua equação, seria:

MVA $=$ valor de mercado - capital próprio $^{11}$

Desse modo, pode-se considerar o MVA como uma medida do desempenho acumulado da empresa em um determinado instante ou como a somatória dos valores presentes de todos os EVAs futuros descontados ao custo de capital próprio.

Erbhar (1999) entende que o MVA busca captar duas atitudes básicas associadas à criação de valor para o acionista:

- exploração eficaz dos recursos captados (aumento do capital total implica a diminuição do indicador), consistentemente com o EVA e

- busca um canal de comunicação com o mercado, objetivando influenciar sua percepção a respeito do valor do empreendimento.

\subsubsection{5- Uma avaliação integrada: a relação entre MVA e EVA}

Desse modo, se o MVA representa a acumulação de riqueza para o acionista, o EVA explicaria as razões dessa acumulação. "Para criar valor para o acionista, a administração precisa gerar sistematicamente EVAs positivos, ou seja, obter excedentes de retorno." (MARTELANC, PASIN,CAVALCANTE, 2005:262)

De acordo com Martins (2001:249)

\footnotetext{
10

${ }^{0}$ citado no artigo "Hey, what's that opaque financial institution worth?" ( Afinal, quanto vale uma instituição financeira não transparente?) em http://www.bettermanagement.com/library/library.aspx?libraryid=7245

${ }^{11}$ Para maiores considerações sobre a metodologia do cálculo do MVA, ver MARTINS, 2001 p. 248 e seguintes.
} 
é nesse contexto que o EVA e o MVA se relacionam. Ambos incorporam a mesma intenção de uso eficaz dos recursos captados. Contudo, enquanto o segundo mede a percepção do mercado sobre os esforços realizados pelos gestores para gerar riqueza, o primeiro constitui-se no canal de comunicação, entre os agentes internos e externos, do compromisso com diretrizes que agregam valor para os sócios, bem como os resultados alcançados.

Póvoa (2004:354) entende que o lucro econômico (EVA) como medida de desempenho é superior ao valor de mercado adicionado (MVA) porque, na medida em que as empresas não podem controlar a reação dos mercados, o MVA - pelo menos no curto prazo - poderia apresentar valores distorcidos com relação ao desempenho que seria caracterizado pelos valores apresentados pelo EVA, ou seja

a companhia pode apresentar maravilhoso desempenhoemumano, comtodososdepartamentos superando suas metas em termos de EVA e, mesmo assim, sua ação cair. Tecnicamente, isto significaria que todo o potencial de agregação de valor naquele ano, construído pelo risco específico, foi mais do que anulado pela destruição de valor advinda do risco de mercado. (PÓVOA,2004:354).

As considerações acima são reforçadas por Ehrbar (1999), quando afirma que

o caminho[...] é gerenciar visando aumentos de EVA, porque EVA é a medida interna de desempenho mais estreitamente relacionada ao MVA e oferece a indicação mais confiável de se - e em quanto - as ações da gerência contribuirão para a riqueza dos acionistas.
Damodaran (1997) conclui que a vantagem do método EVA está em sua simplicidade. Ele reúne um grande número de variáveis e interações presentes em um fluxo de caixa, descontado em apenas duas variáveis (retorno sobre o capital e custo do capital), e uma interação (a diferença entre as duas variáveis).

Ressaltada a simplicidade do EVA e, entendendo que sua utilização não seria isolada, mas em conjunto com outras medidas de lucratividade e desempenho, pode-se então sugerir sua adoção como um índice de benchmarking financeiro.

Como observado anteriormente, Stewart (1991) considera que o EVA fornece medidas significativas para se progredir na criação de valor e servir como benchmark na mensuração da perfomance de toda e qualquer companhia.

\section{6- Conclusão: o benchmarking financeiro e a Administração estratégica}

Pode-se concluir que o ponto de convergência do benchmarking financeiro é a Administração estratégica entendida aqui tanto como a formulação, como a implementação da estratégia empresarial. Portanto, o grande desafio é associar as métricas de avaliação financeira (benchmarks) à estratégia empresarial.

Do exposto, pode-se argumentar com Martelanc, Pasin, Cavalcante (2005:240), que a adoção do EVA como parâmetro de benchmarking financeiro permitiria a integração entre a Administração Estratégica e a Administração Financeira. Assim, faz-se convergir no processo de Administração Estratégica as práticas de benchmarking como ilustrado na Figura 4 que se segue: 


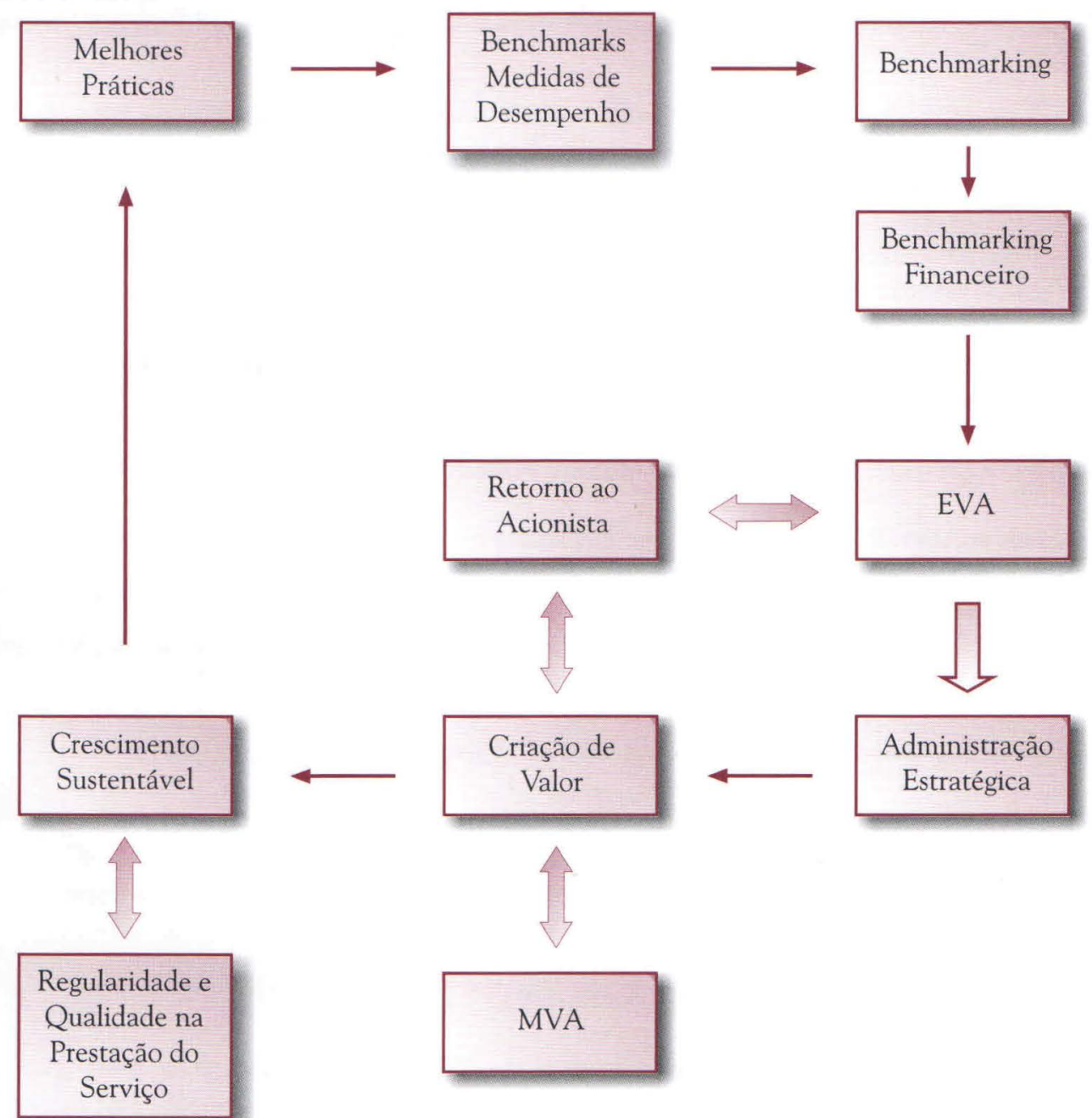

Figura 4- Integração da Administração Financeira e Administração Estratégica

Articulam-se, desse modo, os objetivos empresariais com as medidas de desempenho e incentivos financeiros que orientam as decisões gerenciais, de modo a garantir criação de valor para seus acionistas e proporcionar às empresas um crescimento sustentável que assegure a oferta de produtos e ou serviços com regularidade e qualidade.

\section{REFERÊNCIAS BIBLIOGRÁFICAS}

"Hey, what's that opaque financial institution worth?" (Afinal, quanto vale uma instituição financeira pouco transparente?) em http://www.bettermanagement.com/library/library.aspx?libraryid=7245. Acesso em: 28 dez. 2005.

Benchmarking, 2005 in http://www.bambooweb.com/articles/b/e/Benchmarking.html. Acesso em: 23 dez. 2005.

CAMP, R.C. Benchmarking: The search for Industry Best Practices That Lead to Superior Performance American Society for Quality Control. Quality Press: Milwaukee,WI, 1989 citado PYZDEK, T. Benchmarking from The Handbook for Quality Management Tucson: Quality Publishing, Inc.,2002 Part $1 \mathrm{em}$ http://www.bettermanagement.com/libray.aspx?pagetype=1\&lybrayid=4620. Acesso em: 14 out. 2004. 
CAMP, R.(1989) Benchmarking: The search for industry best practices that lead to superior performance, American Society for Quality Control, Quality Press, Milwaukee, Wis.,1989 in http://www.bambooweb.com/articles/s/t/Strategic_management.html. Acesso em: 22 dez. 2005.

DAMODARAN, A. A avaliação de investimentos: ferramentas e técnicas para a determinação do valor de qualquer ativo. Rio de Janeiro: Qualitymark, 1997 apud Martelanc,R., Pasin,R.,Cavalcante,F. Avaliação de empresas: um guia para fusões \& aquisições e gestão de valor. São Paulo: Pearson Prentice-Hall, 2005.

EHRBAR, A. EVA - valor econômico agregado: a verdadeira chave para a criação de riqueza. Rio de Janeiro: Qualitymark, 1999 apud MARTINS, E. Avaliação de empresas: da mensuração contábil à econômica. São Paulo: Atlas, 2001.

GITMAN,L.J. Princípios de Administração Financeira. 7. ed. São Paulo: Harbra, 2002. Disponível em:

http://www.bambooweb.com/articles/b/e/Benchmark.html. Acesso em: 23 dez. 2005.

LACOMBE, FJ.M; HEILBORN, G.L.J. Administração: Princípios e Tendências. São Paulo: Saraiva, 2003. 542p.

LESTER, R. (1989) Made in America, MIT Commission on Industrial Productivity, Boston, 1989. Disponível em: http://www.bambooweb.com/articles/s/t/Strategic_management.html. Acesso em: 23 dez. 2005.

MARTELANC, R., PASIN,R.,CAVALCANTE,F. Avaliação de empresas: um guia para fusões \& aquisições e gestão de valor. São Paulo: Pearson Prentice-Hall, 2005.

MARTINS, E. Avaliação de empresas: da mensuração contábil à econômica. São Paulo: Atlas, 2001.

PÓVOA, A. Valuation: como precificar ações. São Paulo: Globo, 2004.

SISSON, K., ARROWSMITH, J., MARGINSON, P. All benchmarkers now? Benchmarking and the 'Europeanisation' of industrial relations. Industrial Relations Journal, v..34, pp.15-31, March 2003.

SPENDOLINI, M.J. Benchmarking. São Paulo: Makron Books ,1993.

STEWART, G.B. The quest for value: the EVA management guide. Nova York: HarperCollins, 1991 apud Martelanc,R., Pasin,R.,Cavalcante,F. Avaliação de empresas: um guia para fusões \& aquisições e gestão de valor. São Paulo: Pearson Prentice-Hall, 2005.

STEWART, G.B. The quest for value: the EVA management guide. New York: Harper Business, 1991 apud MARTINS, E. Avaliação de empresas: da mensuração contábil à econômica. São Paulo: Atlas, 2001. 